\title{
NOTES ON THE SOUTH AMERICAN IAACTICAS.
}

\author{
By F. C. Bowditch, \\ Boston, Mass.
}

In Psyche, volume xx page $12 \%$, is given a list of the Lacticas of the Stanford Expedition to Brazil. One of the chief characteristics of the genus as originally laid out, is the transverse groove of the thorax, abruptly terminated by a longitudinal cut; soon, however, forms turned up where this transverse groove was much modified, then were added forms like thoracica Jac. where it was almost wanting, and the longitudinal cut only indicated; then calcarata Ill. has a well developed spur on the hind tibia ( $\delta$ only), then a species appeared with anterior oblique depressions on the thorax (impressicollis Jac.), so that the genus as originally planned has been a good deal modified. Among the species undetermined in the above list are:

rubricata Illig., 1 pair, Para.

debilis Har., 1 Madeira Mamore, No. 2219 Thaxter.

trapezophorus Schf., 1 Porto Velho Rio Madeira, No. 2239 Thaxter.

This last species has two foveac on the front and seems rare in collections-though it may be that what seems a fovea is merely the rear of the not uncommon ocular sulcus, covered somewhat by the withdrawal of the head into the thorax.

\section{Lactica brunneipennis sp. nov.}

Oblong, medium sized, head, legs and antennæ black; thorax, body below and elytra bright shining reddish-yellow, the latter on either side, with a wide black longitudinal median stripe, starting from the base and extending nearly to the apex, the dark color especially on the disk, being beautifully shaded into the red ground color.

1 ( ô ) Rio Madeira, Brazil, Mann and Baker, length $4 \mathrm{~mm}$.

Head impunctate on the vertex, and coarsely punctate in the deep ocular sulcus at the rear of the eye, antennæ reaching a little beyond the middle of the elytra, the basal two or three joints more or less red, second joint short, half the length of the third, that 
and the fourth about equal, thorax with nearly straight sides and finely punctuate surface, the usual sulci both deep, straight and well defined, elytra very finely and inconspicuously punctulate, and a very obsolete basal depression; the extreme bases of the femora somewhat rufous.

\section{Lactica limbatus sp. nov.}

Ovate, small, pale straw yellow, labrum, antennæ (except the base), vertex and neck, and all the edges of the elytra (including the basal and sutural), very dark reddish, piceous black.

$\hat{o}$ and $q$ Porto Velho Rio Madeira, Brabil (Mann and Baker), length $2 \mathrm{~T} / 2-3 \mathrm{~mm}$.

Head finely punctured on the face, very sparsely on vertex, thickly in the ocular sulcus, antennæ $2 / 3$ as long as body, dilute rufous at base, joints $2,3,4$, increasingly long, thorax with nearly straight sides, surface very finely punctulate, transverse sulcus fairly well marked, the cut-off at the ends as usual better defined and deeper, scutellum pitchy, elytra thickly and finely punctuate, without basal depression, the disk of each elytron of a pale straw color forming a regular oblong spot from base to apex, but not in any place attaining the edges, body below and legs uniformly pale. The elytral markings easily distinguish this form.

\section{Lactica bakeri sp. nov.}

Small, elongate parallel, anterior face, antennæ, thorax and legs pale flavous, tinged (especially the latter) with rufous, rear of head, neck and elytra dark violet, body below greenish-black.

5 examples, Porto Velho, Rio Madeira, Brazil (Mann and Beker), length $23 / 4-31 / 2 \mathrm{~mm}$.

Mouth parts, and antennæ exteriorly, darkened with rufous, vertex with scattered punctures, sulcus of eye more thickly punctate; antennæ reaching a little below the middle of elytra, joints rather stout and flattened, the apex of each joint with stiff hairs, thorax with slightly rounded sides, a few fine punctures on the disk, usual sulci, prominent, deep and straight, elytra parallel, without basal depression sparsely punctulate. The Mexican species hidalgoensis Jac. has the same coloration of the elytra but has the head and body below flavous. 


\section{Lactica spinifer sp. nov.}

Stout, like calcarata Ill. or thoracica Jac. entirely flavous with black eyes (antennæ except first joint missing), hind tibia with a stout spur-like process (like calcarata) placed a trifle behind the middle on the inside.

1 example Chancomayo Thamm (first Jac. coll.), length $4 \mathrm{~mm}$.

Head with a small median fovea, and a few punctures on the front and vertex, thorax sparsely, finely punctulate, sides nearly straight, basal sulcus only moderately deep, the lateral deeply foveate; elytra smooth, polished, sparsely, finely punctulate and with a slight basal depression.

The tibial spur easily distinguishes this form.

In Ann. de Belg. 1893, Mr. Jacoby describes Lactica thoracica, a Bolivian form, as having the thorax "without any basal sulcus, the lateral grooves just indicated." My specimen came from Cachabe; it is the best example of the absence of the basal sulcus. Another form with the same characteristic is

Lactica plagiata sp. nov.

Ovate, convex, flavous, palpi, antennæ, legs and breast pitchy black, elytra with a large common blue-black spot from the base to below the middle, leaving a narrow strip of the margin flavous, the rear edge of the spot straight.

3 examples, 2 ô 1 \%, Cachabè l. c. (Rosenberg), length 4-5 mm.

Head with well marked carina between the antennæ, front smooth, except for a few punctures, antennæ reaching below the middle of the elytra, second joint small, the first two joints somewhat testaceous below, thorax with straight sides, smooth and shining above, with a few minute punctures, the basal sulcus barely indicated (it might be called absent), the lateral grooves slightly indented; elytra smooth, convex, lightly punctulate, thickly on the yellow area at the tip. In what I consider the $q$ the hind legs are much more strongly developed than in the $\hat{o}$ and the apex of the hind tibia is broadened and flattened on the inside. The thoracic structure is almost identical with that of thoracica Jac.

Sellata Baly is a well known form, widely distributed in Brazil. A species much resembling it superficially I separate as 

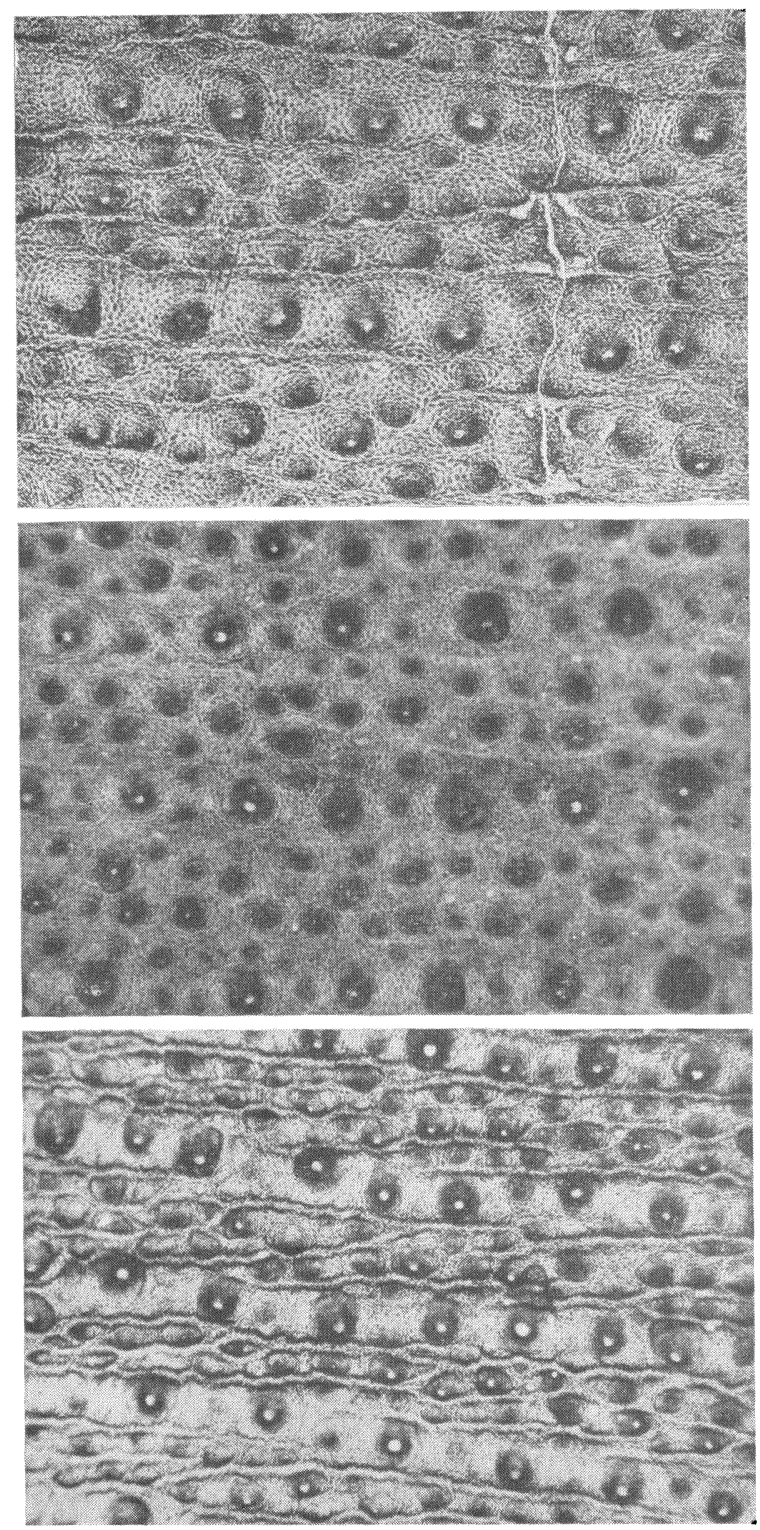

BRUES-Paraperipatus lorentzi. 


\section{Lactica dilatipes sp. nov.}

Small, oblong, light straw- yellow, antennæ, except the base, most of the tibæ and tarsi and a common triangular spot on the base of the elytra, dark piceous, hind tibia of $\hat{o}$ abruptly dilated, inside, near the tip (like some species of Colaspis).

5 of $2 q$, Salinas Beni R. (Stuart), length $3 \frac{1}{2}-4 \mathrm{~mm}$.

Head with a broad, smooth front, with a few fine punctures, antennæ relatively stout, reaching the middle of the elytra, second joint nearly equal to the third, thorax with nearly straight sides very finely punctulate, sulci well marked, especially the lateral; elytra, smooth, shining, very minutely punctulate, basal depression slight, the dark spot does not cover the scutel, but touches the base in either side, running round under the shoulder, and a straight line across the middle; distinguished from sellata by the light legs and dilated $\hat{\sigma}$ tibia; the punctuation of the $q$ is stronger than the $\hat{o}$.

Lactica seminigra Jac. P. Z. S. p. 1\%6, is a preoccupied name and should be changed to Rosenbergi. The $\hat{o}$ hind tibia is ditinctly curved and has a large spur-like process on the inside middle, like calcarata Ill. In thoracica. Jac. what I take to be the $\hat{o}$ has a well marked dilation of the hind tibia close to the tip.

The general shape of the body and the absence or otherwise of the ocular sulcus may be hereafter an aid in the future arrangement or division of the species of this perplexing group.

\section{ON PARAPERIPATUS LORENTZI HORST AND OTHER SPECIES OF THE GENUS FROM NEW GUINEA AND CERAM. ${ }^{1}$ \\ By Charles T. Brues.}

Mr. Frederick Muir forwarded to me some time ago three specimens of Peripatus collected by Mr. A. F. Pratt in the Arfak Mountains, Dutch New Guinea.

1 Contribution from the Entomological Laboratory of the Bussey Institution, Harvard University, No. 182. 

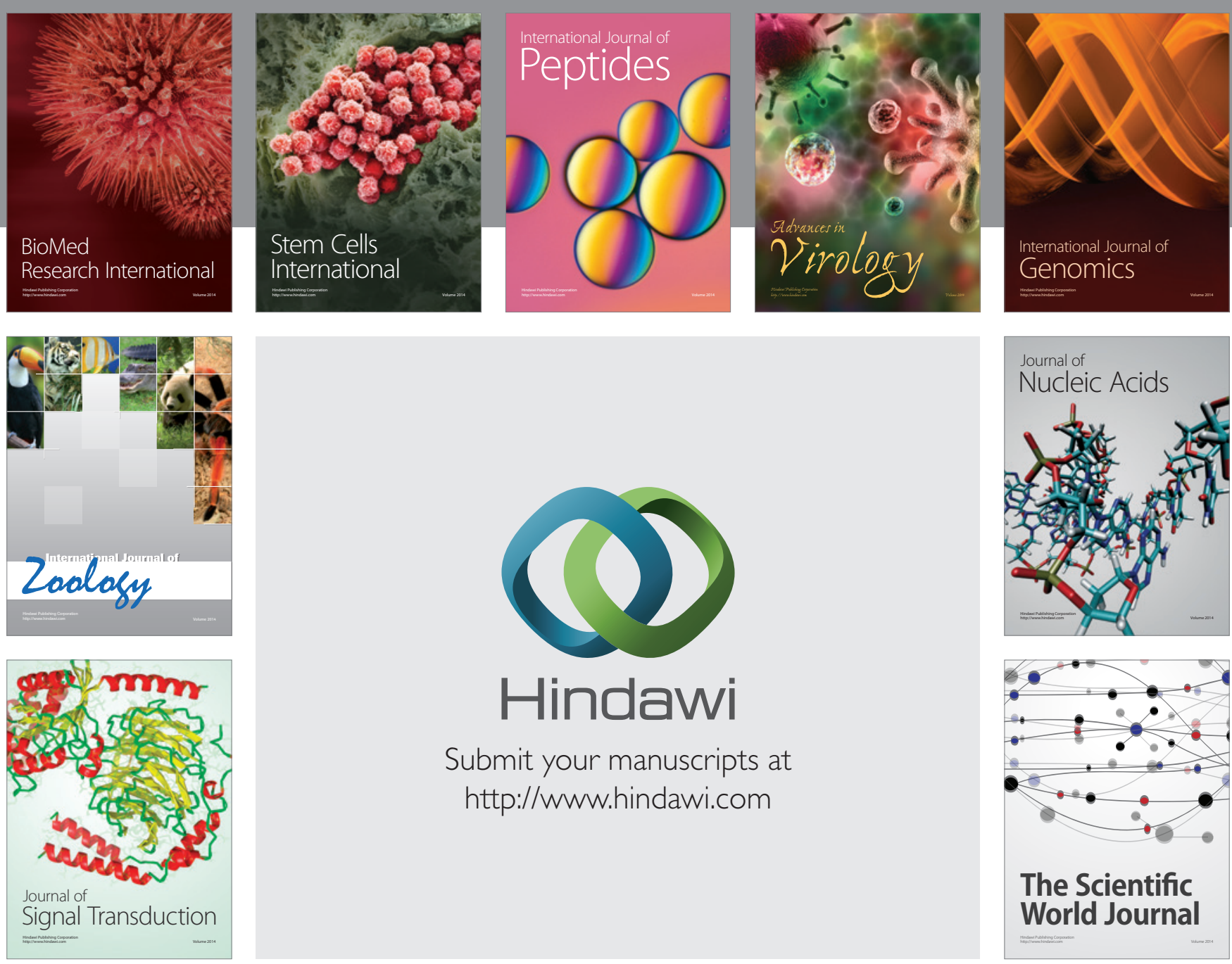

Submit your manuscripts at

http://www.hindawi.com
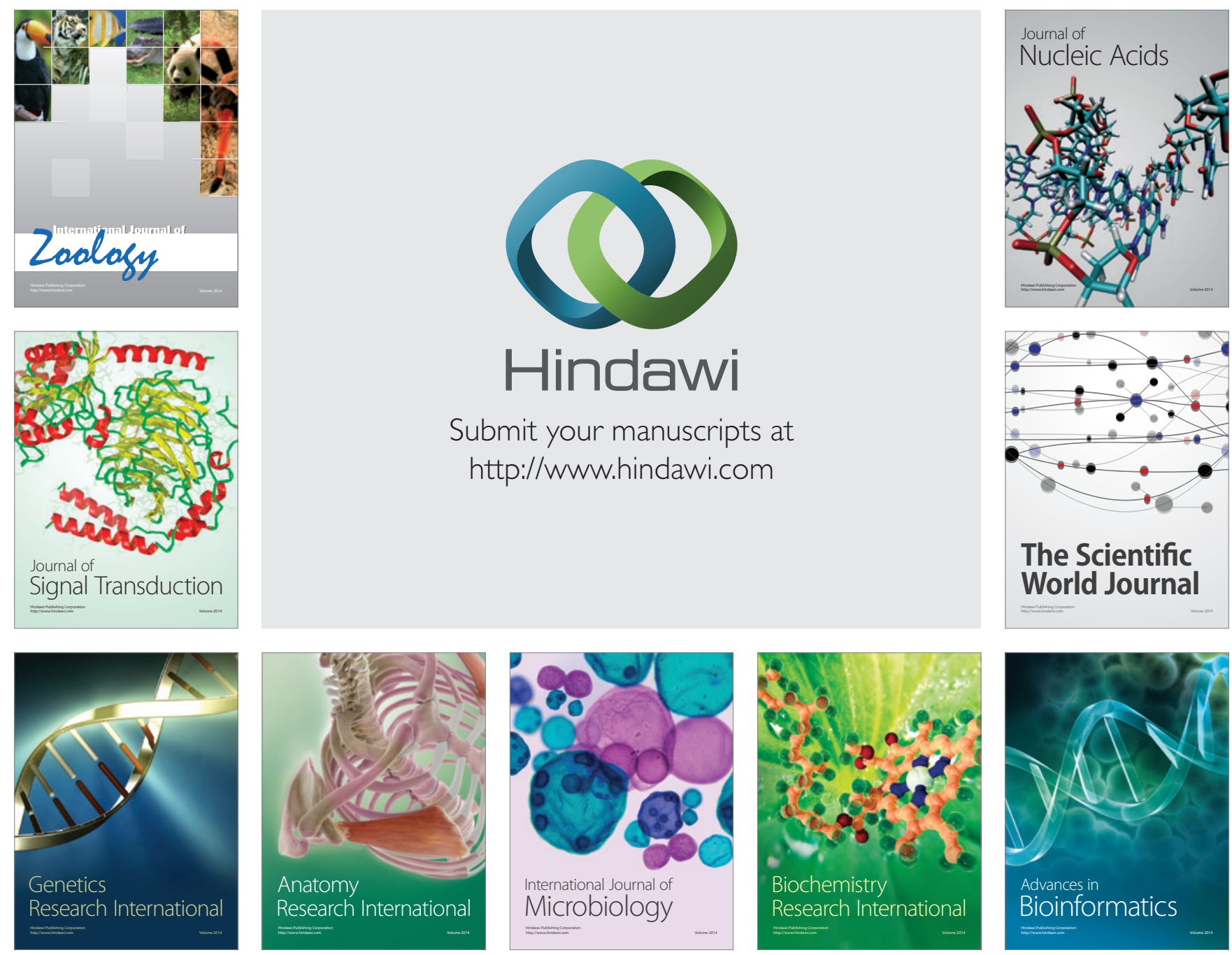

The Scientific World Journal
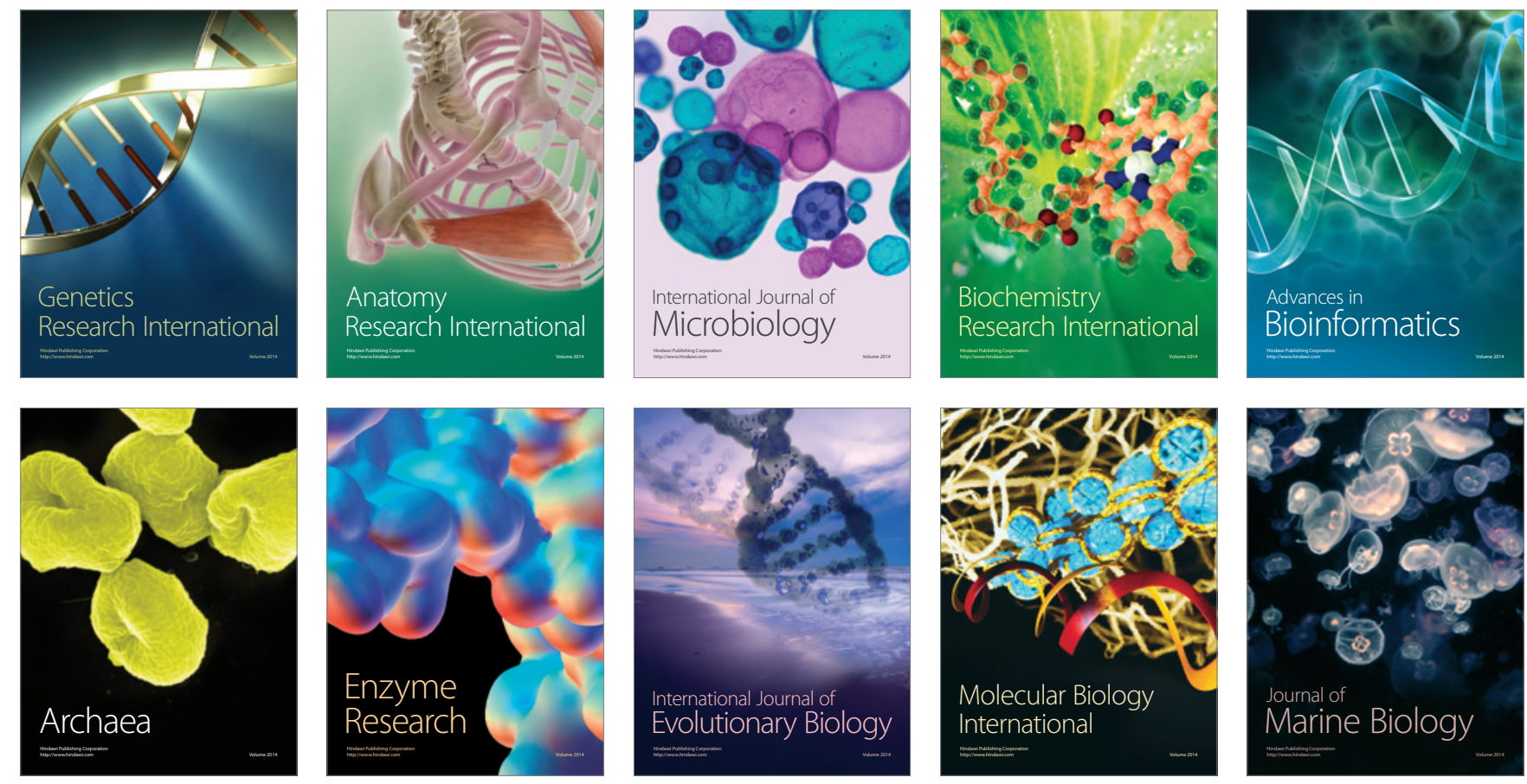